\title{
The Optimization of Chiller Loading by Adaptive Neuro-Fuzzy Inference System and Genetic Algorithms
}

\author{
Jyun-Ting Lu, Yung-Chung Chang, and Cheng-Yi Ho \\ Department of Energy and Refrigerating Air-Conditioning Engineering, National Taipei University of Technology, \\ No.1, Section 3, Zhongxiao E. Road, Taipei 10608, Taiwan
}

Correspondence should be addressed to Jyun-Ting Lu; rasheed0701@hotmail.com

Received 8 May 2015; Accepted 21 June 2015

Academic Editor: Zhike Peng

Copyright (C) 2015 Jyun-Ting Lu et al. This is an open access article distributed under the Creative Commons Attribution License, which permits unrestricted use, distribution, and reproduction in any medium, provided the original work is properly cited.

A central air-conditioning (AC) system includes the chiller, chiller water pump, cooling water pump, cooling tower, and chilled water secondary pumps. Among these devices, the chiller consumes most power of the central AC system. In this paper, the adaptive neuro-fuzzy inference system (ANFIS) and genetic algorithm (GA) were utilized for optimizing the chiller loading. The ANFIS could construct a power consumption model of the chiller, reduce modeling period, and maintain the accuracy. GA could optimize the chiller loading for better energy efficiency. The simulating results indicated that ANFIS combined with GA could optimize the chiller loading. The power consumption was reduced by $6.32-18.96 \%$ when partial load ratio was located at the range of $0.6 \sim 0.95$. The chiller power consumption model established by ANFIS could also increase the convergence speed. Therefore, the ANFIS with GA could optimize the chiller loading for reducing power consumption.

\section{Introduction}

The air-conditioning system is highly demanded in human's life and industrial process. However, it consumes electrical power with the ratio around $50 \%[1,2]$. Therefore, how to reduce the power consumption of air-conditioning system may be one of the most important issues to utilize the $\mathrm{AC}$ system and achieve energy. The AC system includes window, separating, and central types. Among them, the central type is suitable for office and factory and so forth.

A central air-conditioning system includes the chiller, chiller water pump, cooling water pump, cooling water tower, and chilled water secondary pumps. Among these devices, the chiller consumes most power of the central airconditioning system. The consumed energy is related to the loading of system.

There were several literatures discussing how to optimize the chiller loading. Braun et al. (1989) proposed the equal loading distribution (ELD) method. This method was established under the same operating characteristics of chiller [3-5]. Due to the different operating characteristics of the chiller, Braun et al. suggested that the power consumption of the chiller was correlated with load of air conditioners, cooling water return temperature, and chiller water supply temperature. This correlation may explain the optimal chiller loading (OCL) method. Chang et al. (2005) adopted partial load ratio (PLR) method as gene coding principle of genetic algorithm (GA) to minimize power consumption of the chiller, which served as an objective function. The results showed that Lagrangian multiplier method (LGM) could converge the low load conditions and achieve high accuracy performance [6]. Bonissone et al. (2006) discussed implicit and explicit knowledge representation mechanisms for evolutionary algorithms and applied domain customized mutation operators for a well-sampled Pareto front showing all the nondominated solutions [7]. Haber and Alique (2007) applied fuzzy-logic for torque control system, embedded in an open-architecture computer numerical control (CNC) [8]. Martín et al. (2009) proposed GA applied to the networked control of a high performance drilling process for optimal tuning of a linear controller [9]. Lee and Lin (2009) applied particle swarm optimization (PSO) method for optimizing the chiller loading, design, and operating strategies of airconditioning system [10]. Lee et al. (2011) compared the results of differential evolution algorithm with equal loading distribution, as well as LGM and PSO [11]. Gajate et al. 
(2012) proposed two model-based approaches for tool wear monitoring on the basis of neuro-fuzzy techniques. The comparative study demonstrates that the transductive neurofuzzy model provides better error-based performance indices [12]. Chen et al. (2014) utilize neural networks (NN) to establish the power consumption model of the chiller and PSO for optimal loading and saving energy [13].

From the previous studies, the equal loading distribution method was often used to reduce power consumption. However, the LGM may cause system divergence. The NN method adopted try-and-error principle to find number of better neurons on a hidden layer. It may cause longer period. Hence, there is no single method suitable for all the conditions.

In the study, the ANFIS combined with GA are utilized to optimize the chiller loading and reduce the power consumption and operating period.

\section{System Architecture}

The general decoupled system of a central air-conditioning system is shown in Figure 1 [14]. The common piping is the division line of the central air-conditioning system. For separating the system into two parts, including the first side (chiller side) and secondary side (load side), the first side contains the chiller and chiller water pump, and the secondary side is chilled water secondary pumps and air handing unit. The secondary variable frequency pump is installed on the secondary side for controlling the flow speed to improve energy efficiency. The total load of this system can be expressed by

$$
\mathrm{CL}=\dot{m} C_{p}\left(T_{\text {chwr }}-T_{\text {chws }}\right),
$$

where CL is the cooling load $(\mathrm{kW}), \dot{m}$ is the flow rate of chiller water $(\mathrm{kg} / \mathrm{s}), C_{p}$ is the specific heat capacity of chilled water $(\mathrm{J} / \mathrm{kg} \cdot \mathrm{K}), T_{\text {chwr }}$ is the cooling water return temperature $(\mathrm{K})$, and $T_{\text {chws }}$ is the chilled water supply temperature $(\mathrm{K})$.

\section{Chiller Power Consumption Model}

Generally speaking, the capacity of the chiller is designed to meet the need of peak load. However, most of the chiller is operated under the condition of partial load, and this would result in larger designed capacity and power consumption. The partial load ratio of a chiller is defined in

$$
\text { PLR }=\frac{\text { cooling load }}{\text { chiller capacity }}
$$

The variables of the power consumption model include chilled water supply temperature, cooling water return temperature, and partial load ratio. The power consumption model could be presented in [15]

$$
\begin{aligned}
P_{\mathrm{ch}, i}= & a_{0, i}+a_{1, i}\left(T_{\mathrm{chwr}, i}-T_{\mathrm{chws}, i}\right) \\
& +a_{2, i}\left(T_{\mathrm{chwr}, i}-T_{\mathrm{chws}, i}\right)^{2}+a_{3, i} \mathrm{PLR}_{\mathrm{ch}, i} \\
& +a_{4, i} \mathrm{PLR}_{\mathrm{ch}, i}^{2}+a_{5, i}\left(T_{\mathrm{chwr}, i}-T_{\mathrm{chws}, i}\right) \mathrm{PLR}_{\mathrm{ch}, i},
\end{aligned}
$$

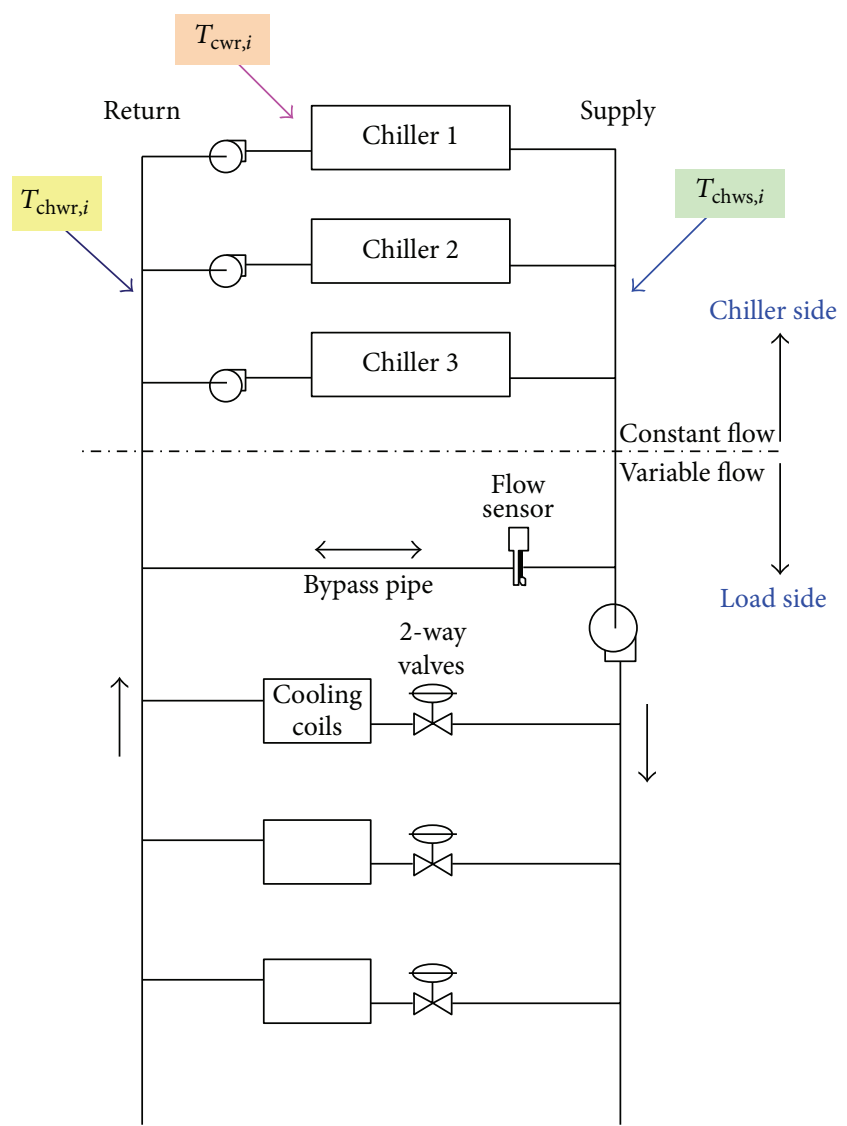

Figure 1: Decoupled system of a central AC system [14].

where $a_{0, i} \sim a_{5, i}$ is the regression coefficient, $T_{\text {chwr }, i}$ is the cooling water return temperature, $T_{\text {chws }, i}$ is the chilled water supply temperature, and $\mathrm{PLR}_{\mathrm{ch}, i}$ is the partial load ratio. All of these parameters are for the $i$ th chiller.

The chiller power consumption model could be established by ANFIS. The program could be expressed by

$$
P_{\mathrm{ch}, i}=f\left\{\left(T_{\mathrm{chwr}, i}-T_{\mathrm{chws}, i}\right), \operatorname{PLR}_{\mathrm{ch}, i}\right\} .
$$

After establishing the power consumption model, in order to satisfy OCL, the minimum power consumption of the chiller could be viewed as the objective function. The objective function could be presented by

$$
\text { Objective function }=\operatorname{Min} \sum_{i}^{n} P_{\mathrm{ch}, i},
$$

where $n=$ set number of operating chiller (set).

The restrictive limitations could be presented in

$$
\mathrm{CL}=\sum_{i=1}^{n}\left(\mathrm{PLR}_{\mathrm{ch}, i} \times \text { chiller }_{\text {capacity }, i}\right),
$$

0.5 (Low Limit) $\leqq \mathrm{PLR}_{\mathrm{ch}, i} \leqq 1$ (Upper Limit)

In order to prevent the low operating efficiency and surge of the chiller, the chiller could be set to the lowest load (PLR = $0.5)$. Conversely, when the PLR was greater than or equal to 1 , the load of the chiller would be full. 


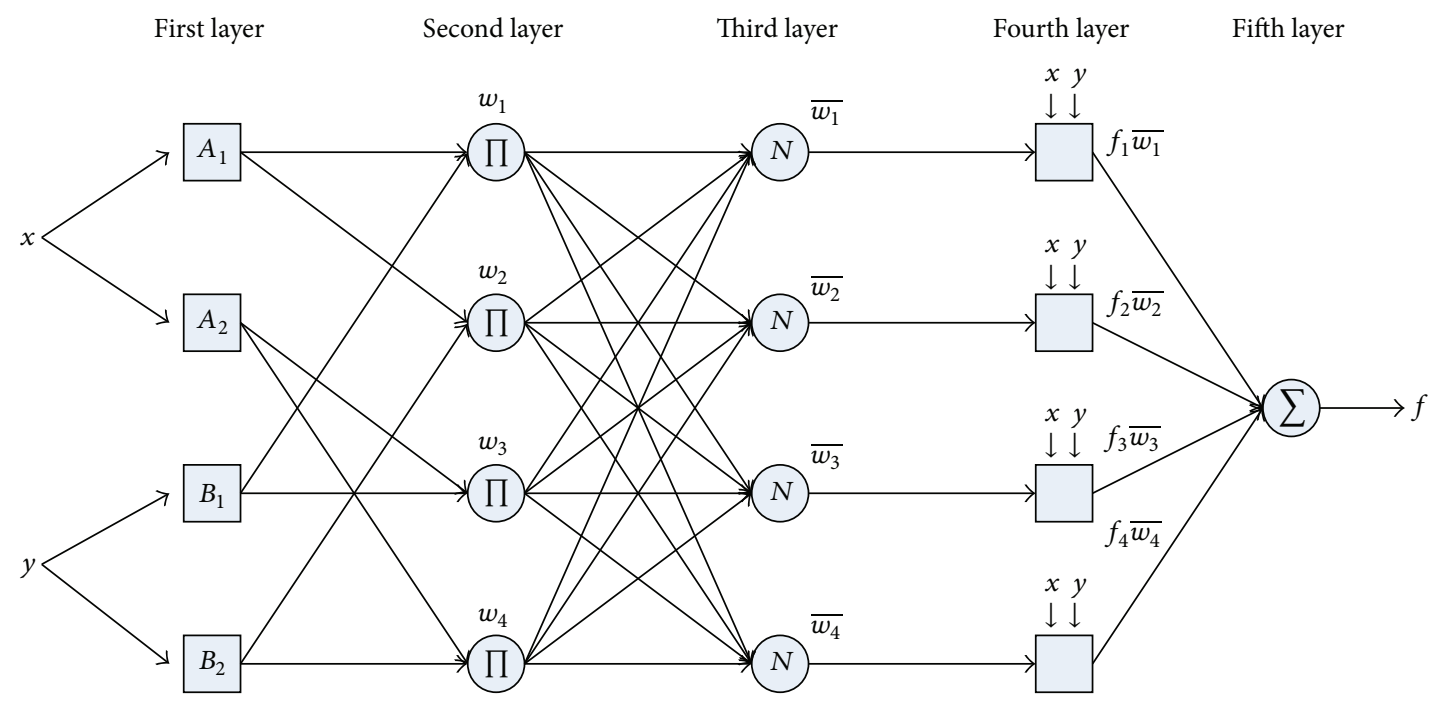

FIgURE 2: ANFIS architecture of the one order Sugeno fuzzy model.

\section{Analysis Method}

4.1. Adaptive Neuro-Fuzzy Inference System (ANFIS). The ANFIS was proposed by Jang [16] in 1993 and combined the NN and fuzzy methods. ANFIS has been used to solve the difficulty of traditional fuzzy system in defining fuzzy rule base using expert experience, establish the if-then rules based on hybrid learning procedure, and adjust suitable regression function to satisfy input-output relationship of fuzzy inference. Moreover, ANFIS have been applied on the NN system to determine the number of neurons in hidden layer during initialization. The proper number of neurons can be found by try-and-error.

Figure 2 demonstrated the ANFIS architecture with fuzzy inference of the one order Sugeno fuzzy model. In Figure 2, the nodes of each layer had the same function.

The functions of five layers are described as follows:

(1) First layer: membership function of inputs $x$ and $y$, as described by

$$
\mu_{A}(x)=\frac{1}{1+\left|\left(x-c_{i}\right) / a_{i}\right|^{2 b_{i}}},
$$

where $a_{i}, b_{i}$, and $c_{i}$ are the premise parameters.

(2) Second layer: multiplication of the input signals, as described by (8).

It represents the firing strength of each fuzzy rule:

$$
w_{i}=\mu_{A_{j}}(x) \cdot \mu_{B_{j}}(y), \quad i=1 \sim 4, j=1,2 .
$$

(3) Third layer: normalization of $i$ th fuzzy rule's firing strength, as described by

$$
\overline{w_{i}}=\frac{w_{i}}{\sum_{i=1}^{4} w_{i}}, \quad i=1 \sim 4 .
$$

(4) Fourth layer: node function described by

$$
\overline{w_{i}} f_{i}=\bar{w}_{i}\left(p_{i} x+q_{i} y+r_{i}\right), \quad i=1 \sim 4 .
$$

(5) Fifth layer: summation of previous layer as the output, as described by

$$
f=\sum_{i=1}^{4} f_{i} \overline{w_{i}}, \quad i=1 \sim 4 .
$$

In Figure 2, the ANFIS architecture was composed of two input variables $(x, y)$ and one output $(f)$. Each input had two membership functions and composed four fuzzy rules, totally.

In this study, the temperature differences between cooling water return temperature $\left(T_{\text {chwr }}\right)$, chilled water supply temperature $\left(T_{\text {chws }}\right)$, and partial load ratio were assumed as the input variables. Power consumption was assumed as the output variable. Each input had three membership functions and composed nine fuzzy rules, totally.

The software programs of Matlab, Mathematica 5, and Fuzzy Logic Toolbox were adopted to build the model for simulation. The ANFIS training flow chart was shown in Figure 3. First, the operating conditions of chiller were collected, and the proper training data was selected. Then, the ANFIS parameters were set and trained through the loop. When the iteration number was achieved, the ANFIS training was completed.

4.2. Genetic Algorithm (GA). GA was proposed by Holland et al. in 1970 and based on Darwin's doctrine of evolution, natural selection, and survival of the fittest [6]. GA mainly transforms problems into gene permutation and continuously optimizes them through selection or reproduction, crossover, and mutation. The algorithm could seek optimal solution through parallel search in wide solution domain and has been widely applied on various fields.

4.2.1. Characteristics of GA. GA is different from the traditional optimization method and has the characteristics 


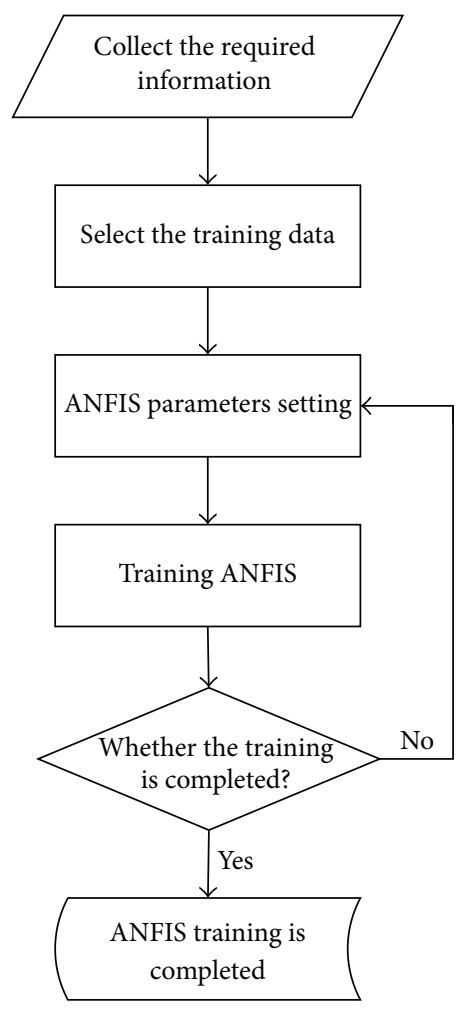

FIgURE 3: ANFIS training flow chart.

of stability and efficiency. The main features are shown as follows.

(1) Prevent Complicated Mathematical Model Deviation. For calculation, fitness function is used as the measuring standard to prevent complicated mathematical model deviation.

(2) Convergence Speed for Calculation. The parallel search method is used for calculating parameter. Instead of singlepoint method, multipoint method can be performed at the same time to accelerate convergence speed for calculation.

(3) Prevent Local Optimal Solution. GA includes mutation operation. Chromosomes could practice the mutation change during evolution to prevent local optimal solution in search process.

\section{Case Analysis and Results}

In this paper, a semiconductor factory with five chillers was under investigation. The specifications of these chillers are shown in Table 1 . The operating conditions of these chillers, including power consumption, the temperature at chilled water supply, and cooling water return, were recorded every 5 min during entire experiments. There are totally 10580 data sets in the experiments.

5.1. Chiller Power Consumption Model Using Regression Anal$y$ sis. The linear regression (LR) analysis method is utilized to build and analyze the power consumption model of the
TABLE 1: Operating conditions of chiller system.

\begin{tabular}{lccccc}
\hline Chiller & 1 & 2 & 3 & 4 & 5 \\
\hline $\begin{array}{l}\text { Chiller water supply } \\
\text { temperature }\left({ }^{\circ} \mathrm{C}\right)\end{array}$ & 5 & 5 & 5 & 5 & 5 \\
$\begin{array}{l}\text { Cooling water return } \\
\text { temperature }\left({ }^{\circ} \mathrm{C}\right)\end{array}$ & 28 & 28 & 28 & 28 & 28 \\
$\begin{array}{l}\text { Chiller water flow rate } \\
\left(\mathrm{m}^{3} / \mathrm{hr}\right)\end{array}$ & 531 & 501 & 567 & 521 & 528 \\
$\begin{array}{l}\text { Cooling water flow rate } \\
\left(\mathrm{m}^{3} / \mathrm{hr}\right)\end{array}$ & 705 & 742 & 698 & 722 & 674 \\
$\begin{array}{l}\text { Cooling capacity }(\mathrm{RT}) \\
\text { Voltage }(\mathrm{V})\end{array}$ & 1,280 & 1,280 & 1,280 & 1,250 & 1,250 \\
\begin{tabular}{l} 
Input power $(\mathrm{kW})$ \\
\hline
\end{tabular} & 1,160 & 4,160 & 4,160 & 4,160 & 4,160 \\
\end{tabular}

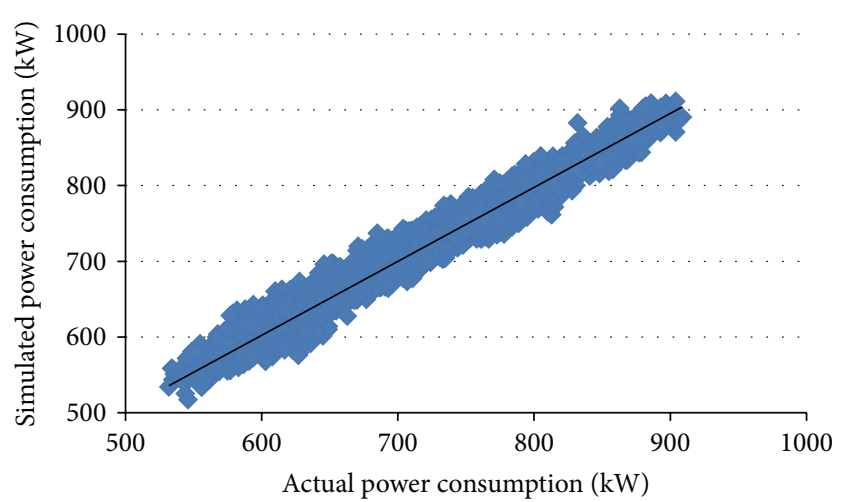

FIgURE 4: Distribution of actual power consumption and simulated power consumption of chiller 1 by using regression analysis.

chiller system with accurate prediction in short-term period [17]. In this study, the software of Mathematica 5 was used to establish regression analysis model. The calculated regression coefficients, $R^{2}$ (coefficient of determination), and average percentage error (err\%) are shown in Table 2. In Table 2, $a_{0} \sim a_{5}$ are curve coefficients of the chiller system in (3) by the regression analysis. Figure 4 shows the relationship between simulated power consumption and actual power consumption of chiller 1 . In the actual power consumption range from 520 to $920 \mathrm{~kW}$, the simulated power consumption by $\mathrm{NN}$ increases from 520 to $920 \mathrm{~kW}$, with the averaged $R^{2}$ and percentage error (err\%) of 0.985 and $0.973 \%$, respectively. For the above main modeling parameters $R^{2}$ and err\%, the temperature differences between cooling water return temperature $\left(T_{\text {chwr }}\right)$, chilled water supply temperature $\left(T_{\text {chws }}\right)$, and partial load ratio were assumed as the independent variables.

5.2. Chiller Power Consumption Model Using NN and ANFIS. NN method is often adopted to build power consumption model of chiller system by try-and-error principle. The ANFIS method is improved from NN method. Therefore, it is in our interest to compare the chiller power consumption model built by regression analysis, NN, and ANFIS methods 
TABLE 2: Coefficients of the chiller power consumption models from quadratic regression analysis.

\begin{tabular}{lccccc}
\hline Chiller & 1 & 2 & 3 & 4 & 5 \\
\hline$a_{0} a_{0}$ & 150.80 & 236.17 & -108.65 & 386.31 & 222.16 \\
$a_{1}$ & 12.79 & -2.08 & 16.21 & -6.19 & -0.80 \\
$a_{2}$ & -0.51 & -0.56 & -0.56 & 0.18 & -0.22 \\
$a_{3}$ & -620.23 & -235.58 & 35.14 & -670.01 & -349.20 \\
$a_{4}$ & 510.82 & -369.19 & -34.55 & 763.31 & 270.52 \\
$a_{5}$ & 49.92 & 81.75 & 44.82 & 28.37 & 47.76 \\
$R^{2}$ & 0.984181 & 0.983730 & 0.985550 & 0.985485 & 0.983580 \\
Error (\%) & 1.420413 & 0.854415 & 0.849768 & 0.845402 & 0.89693
\end{tabular}

TABLE 3: Regression coefficients and average percentage error of chillers by NN model.

\begin{tabular}{lccccc}
\hline Chiller & 1 & 2 & 4 & 5 & 6 \\
\hline$R^{2} R^{2}$ & 0.9998 & 0.9998 & 0.9999 & 0.9998 & 0.9998 \\
err\% & 0.88 & 0.83 & 0.80 & 0.82 & 0.85 \\
\hline
\end{tabular}

TABLE 4: Regression coefficients and average percentage error of chillers by ANFIS model.

\begin{tabular}{lccccc}
\hline Chiller & 1 & 2 & 4 & 5 & 6 \\
\hline$R^{2} R^{2}$ & 0.99988 & 0.99989 & 0.9999 & 0.99989 & 0.99988 \\
err\% & 0.88 & 0.83 & 0.81 & 0.83 & 0.86 \\
\hline
\end{tabular}

in this section. The model of chiller 1 is chosen as an example. Figure 5 shows the relationship between simulated power consumption by $\mathrm{NN}$ method and actual power consumption of chiller 1 . In the actual power consumption range from 520 to $920 \mathrm{~kW}$, the simulated power consumption increases from 520 to $920 \mathrm{~kW}$. The solid line is the fitting curve by least square error method. This fitting method would be applied for the following sections. $R^{2}$ and averaged err\% between data and fitting line are 0.99988 and 0.8769 , respectively.

Figure 6 shows the relationship between simulated power consumption by ANFIS method and actual power consumption of chiller 1 . In the actual power consumption range from 520 to $920 \mathrm{~kW}$, the simulated power consumption increases from 520 to $920 \mathrm{~kW} . R^{2}$ and averaged err\% between data and fitting line are 0.99988 and 0.88359 , respectively.

The calculated $R^{2}$ and err\% of these chillers simulated by $\mathrm{NN}$ and ANFIS methods are shown in Tables 3 and 4, respectively. In Table 3, the range of $R^{2}$ and err\% is from 0.99988 to 0.9999 and from 0.79796 to $0.8769 \%$, respectively. The averaged $R^{2}$ and err\% are 0.99988 and 0.834472 , respectively. In Table 4, the range of $R^{2}$ and err\% is from 0.99988 to 0.9999 and from 0.81413 to $0.88359 \%$, respectively. The averaged $R^{2}$ and err\% are 0.99988 and 0.843964 , respectively.

From Tables 2 to 4 , the simulated results by $\mathrm{NN}$ and ANFIS methods had similar accuracy. The averaged $R^{2}$ by $\mathrm{NN}$ and ANFIS methods are higher than that by regression analysis method. However, the averaged err\% by NN and ANFIS are lower than that by regression analysis method.

In order to understand further the responding time of the utilized methods, the modeling speeds of the chillers

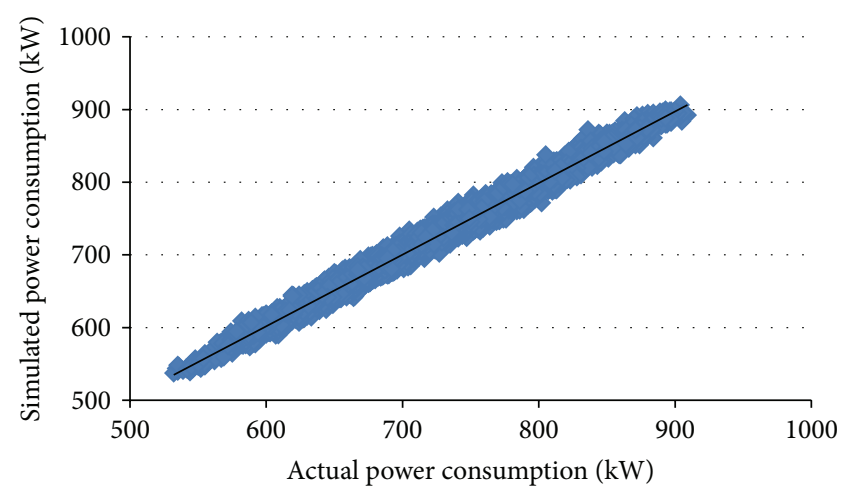

FIGURE 5: Distribution of actual power consumption and simulated power consumption of chiller 1 by using $\mathrm{NN}$.

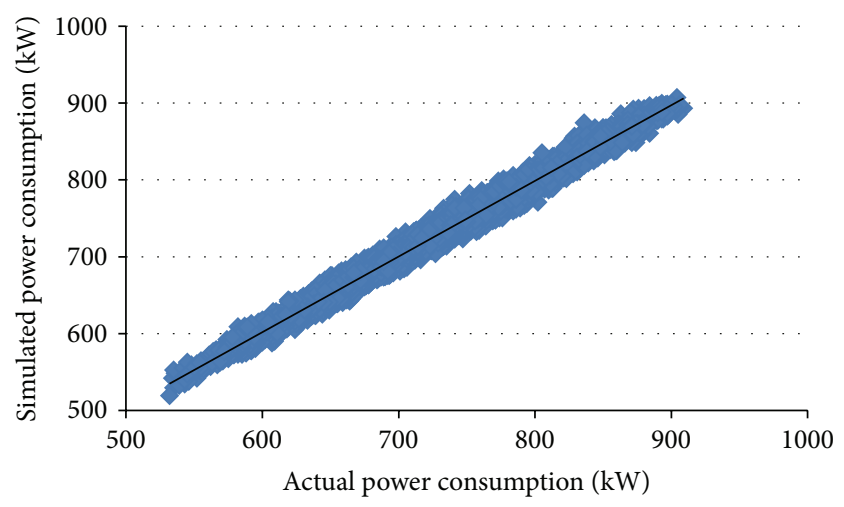

FIGURE 6: Distribution of actual power consumption and simulated power consumption of chiller 1 by using ANFIS.

for semiconductor factory simulated by ANFIS and NN are presented in Table 5 . The chiller power consumption model by using $\mathrm{NN}$ method adopted 40 neurons on a single hidden layer. The output layer of one neuron is utilized for modeling. Based on the results, the iteration period by ANFIS in Table 5 presents more efficient modeling speed, with average of $2 \mathrm{~min}$ $15 \mathrm{sec}$. Therefore, the ANFIS is utilized to design the rule base through automatic learning for achieving optimal output status.

5.3. Loading Distribution Results of $L R+E L D, L R+G A$, $N N+G A$, and ANFIS + GA. LR method could build and analyse power consumption model of the chiller system with accurate prediction. This method includes several order calculation principles. Here, 2nd-order LR method is adopted for calculating multiple parameters with better accuracy [13] The ELD method of equal load is also commonly adopted to operate chillers [3-5]. Therefore, it is in our interest to compare the simulating results by $\mathrm{LR}+\mathrm{ELD}, \mathrm{LR}+\mathrm{GA}, \mathrm{NN}+$ GA, and ANFIS + GA methods.

Table 6 shows the optimal chiller loading by LR + ELD and LR + GA methods under partial load ratio of 0.55 0.95. The results indicated that the LR + GA method had better energy savings than LR + ELD method by $0.77 \%$ to $2.25 \%$ in 
TABLE 5: Chiller modeling speed of NN and ANFIS methods.

\begin{tabular}{|c|c|c|c|c|c|}
\hline Chiller & 1 & 2 & 4 & 5 & 6 \\
\hline NN modeling speed & $3 \mathrm{~min} 30 \mathrm{sec}$ & $3 \mathrm{~min} 27 \mathrm{sec}$ & $3 \min 37 \mathrm{sec}$ & $3 \mathrm{~min} 34 \mathrm{sec}$ & $3 \mathrm{~min} 30 \mathrm{sec}$ \\
\hline ANFIS modeling speed & $2 \min 07 \mathrm{sec}$ & $2 \min 17 \mathrm{sec}$ & $2 \mathrm{~min} 17 \mathrm{sec}$ & $2 \min 17 \mathrm{sec}$ & $2 \min 17 \mathrm{sec}$ \\
\hline
\end{tabular}

the partial load ratios of 0.55 to 0.95 , with the average energy savings of $1.58 \%$. The power consumption of chiller, simulated by LR + ELD and LR + GA methods, increased from 2991 to $5301.3 \mathrm{~kW}$ and from 2967.9 to $5240.8 \mathrm{~kW}$, respectively.

Table 7 shows the optimal chiller loading by LR + ELD and $\mathrm{NN}+\mathrm{GA}$ methods under partial load ratio of $0.55 \sim 0.95$. The results indicated that the NN + GA method had better energy savings than LR + ELD method by $2.63 \%$ to $16.95 \%$ in the partial load ratios of 0.55 to 0.95 , with the average energy savings of $12.14 \%$. The power consumption of chiller simulated by LR + ELD and NN + GA methods increased from 2991 to $5301.3 \mathrm{~kW}$ and from 29127.3 to $4405.2 \mathrm{~kW}$, respectively.

Table 8 shows the optimal chiller loading by LR + ELD and ANFIS + GA methods under partial load ratio of 0.55 0.95 . The results indicated that the ANFIS + GA method had better energy savings than LR + ELD method by $0.36 \%$ to $186.96 \%$ in the partial load ratios of 0.55 to 0.95 , with the average energy savings of $12.84 \%$. The power consumption of chiller, simulated by LR + ELD and ANFIS + GA methods, increased from 2991 to $5301.3 \mathrm{~kW}$ and from 2980.2 to $4296.3 \mathrm{~kW}$, respectively. Table 9 presents the operating conditions of chiller system by using ANFIS + GA method.

From Tables 6 to 8 , the chiller operated by ANFIS + GA method would have better energy savings of $18.96 \%$ among these three methods. This may be due to the better combination capability of GA method for the chiller under partial load ratios to achieve better energy savings.

In order to further understand the relationships of energy usages and savings with these methods, the power consumptions and energy savings of these methods with respect to the partial load ratios are shown in Figure 7. In Figure 7, in the partial load ratio range of 0.55 to 0.95 , the power consumption increased from 2980.2 to $4296.3 \mathrm{~kW}$, from 2912.3 to $4405.2 \mathrm{~kW}$, from 2967.9 to $5240.8 \mathrm{~kW}$, and from 2991 to $5301.3 \mathrm{~kW}$ for ANFIS + GA, NN + GA, LR + GA, and LR + ELD methods, respectively. The chiller simulated by ANFIS + GA method consumed the least power. Compared with LR + ELD, in the partial load ratio range of 0.55 to 0.95 , the energy savings increased from 0.36 to $18.96 \%$, from 2.63 to $16.90 \%$, and from 0.77 to $1.14 \%$ for the simulating methods of ANFIS + GA, NN + GA, and LR + GA, respectively. Among them, the chiller simulated by ANFIS + GA had better energy savings of $12.84 \%$. This may be due to the better inference capability and solving ability of ANFIS method for nonlinear problems and more flexible combinations and better energy saving effect of GA method.

\section{Conclusion}

A central air-conditioning (AC) system includes the chiller, chiller water pump, cooling water pump, cooling tower, and

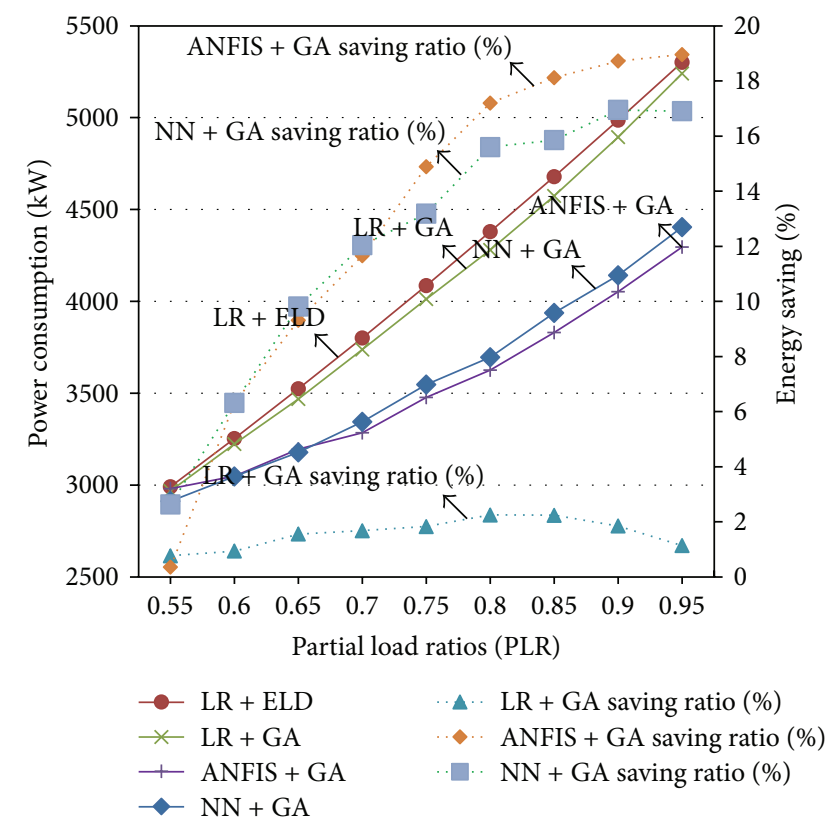

Figure 7: Power consumption between LR + ELD, LR + GA, NN + GA, and ANFIS + GA methods.

chilled water secondary pumps. Among these devices, the chiller consumes most power of the central AC system. In this paper, the adaptive neuro-fuzzy inference system (ANFIS) and genetic algorithm (GA) were utilized for optimizing the chiller loading. The ANFIS could construct a power consumption model of the chiller, reduce modeling period, and maintain the accuracy. GA could optimize the chiller loading for better energy efficiency. The simulating results indicated that ANFIS combined with GA could optimize the chiller loading. The power consumption was reduced by $6.32 \%-18.96 \%$ when partial load ratio was located at the range of $0.6 \sim 0.95$. The chiller power consumption model established by ANFIS could also increase the convergence speed. Therefore, the ANFIS with GA could optimize the chiller loading for reducing power consumption.

The chiller power consumption model established by ANFIS could also increase the convergence speed with average processing period of $2 \mathrm{~min} 15 \mathrm{sec}$. Compared with LR + ELD, ANFIS + GA, NN + GA, and LR + GA methods, the chiller simulated by ANFIS + GA method had better energy savings of $12.84 \%$. This may be due to the better inference capability and solving ability of ANFIS method for nonlinear problems and more flexible combinations and better energy saving effect of GA method. Therefore, the ANFIS with GA could optimize the chiller loading for reducing power consumption. 
TABLE 6: Optimal chiller loading comparison by LRELD and LRGA methods.

\begin{tabular}{|c|c|c|c|c|c|c|c|c|}
\hline \multirow{2}{*}{ Cooling load (RT) } & \multirow{2}{*}{ Chiller } & \multicolumn{3}{|c|}{$L R+E L D$} & \multicolumn{3}{|c|}{$\mathrm{LR}+\mathrm{GA}$} & \multirow{2}{*}{ Saving A - B (\%) } \\
\hline & & PLR & Load (RT) & Total $(\mathrm{kW})(\mathrm{A})$ & PLR & Load (RT) & Total $(\mathrm{kW})(\mathrm{B})$ & \\
\hline \multirow{5}{*}{$6023(95 \%)$} & 1 & 0.95 & 1216 & \multirow{5}{*}{5301.3} & 0.83431 & 1067.92 & \multirow{5}{*}{5240.8} & \multirow{5}{*}{$1.14 \%$} \\
\hline & 2 & 0.95 & 1216 & & 0.99902 & 1278.75 & & \\
\hline & 4 & 0.95 & 1216 & & 0.99951 & 1279.37 & & \\
\hline & 5 & 0.95 & 1187.5 & & 0.92864 & 1160.80 & & \\
\hline & 6 & 0.95 & 1187.5 & & 0.98925 & 1236.56 & & \\
\hline \multirow{5}{*}{$5706(90 \%)$} & 1 & 0.9 & 1152 & \multirow{5}{*}{4986.5} & 0.76197 & 975.32 & \multirow{5}{*}{4894.3} & \multirow{5}{*}{$1.85 \%$} \\
\hline & 2 & 0.9 & 1152 & & 1 & 1280.00 & & \\
\hline & 4 & 0.9 & 1152 & & 0.99951 & 1279.37 & & \\
\hline & 5 & 0.9 & 1125 & & 0.85924 & 1074.05 & & \\
\hline & 6 & 0.9 & 1125 & & 0.87781 & 1097.26 & & \\
\hline \multirow{5}{*}{$5389(85 \%)$} & 1 & 0.85 & 1088 & \multirow{5}{*}{4679.1} & 0.67253 & 860.84 & \multirow{5}{*}{4574.4} & \multirow{5}{*}{$2.24 \%$} \\
\hline & 2 & 0.85 & 1088 & & 1 & 1280.00 & & \\
\hline & 4 & 0.85 & 1088 & & 1 & 1280.00 & & \\
\hline & 5 & 0.85 & 1062.5 & & 0.80303 & 1003.79 & & \\
\hline & 6 & 0.85 & 1062.5 & & 0.77175 & 964.69 & & \\
\hline \multirow{5}{*}{$5072(80 \%)$} & 1 & 0.8 & 1024 & \multirow{5}{*}{4379.2} & 0.58798 & 752.61 & \multirow{5}{*}{4280.6} & \multirow{5}{*}{$2.25 \%$} \\
\hline & 2 & 0.8 & 1024 & & 0.99902 & 1278.75 & & \\
\hline & 4 & 0.8 & 1024 & & 0.99902 & 1278.75 & & \\
\hline & 5 & 0.8 & 1000 & & 0.74145 & 926.81 & & \\
\hline & 6 & 0.8 & 1000 & & 0.66813 & 835.16 & & \\
\hline & 1 & 0.75 & 960 & & 0.53666 & 686.92 & & \\
\hline & 2 & 0.75 & 960 & & 0.99902 & 1278.75 & & \\
\hline $4755(75 \%)$ & 4 & 0.75 & 960 & 4086.7 & 1 & 1280.00 & 4012.1 & $1.83 \%$ \\
\hline & 5 & 0.75 & 937.5 & & 0.66569 & 832.11 & & \\
\hline & 6 & 0.75 & 937.5 & & 0.54203 & 677.54 & & \\
\hline & 1 & 0.7 & 896 & & 0.60068 & 768.87 & & \\
\hline & 2 & 0.7 & 896 & & 0.50098 & 641.25 & & \\
\hline $4438(70 \%)$ & 4 & 0.7 & 896 & 3801.6 & 0.99951 & 1279.37 & 3737.6 & $1.68 \%$ \\
\hline & 5 & 0.7 & 875 & & 0.74633 & 932.91 & & \\
\hline & 6 & 0.7 & 875 & & 0.65249 & 815.61 & & \\
\hline & 1 & 0.65 & 832 & & 0.5176 & 662.53 & & \\
\hline & 2 & 0.65 & 832 & & 0.5 & 640.00 & & \\
\hline $4121(65 \%)$ & 4 & 0.65 & 832 & 3523.9 & 0.99951 & 1279.37 & 3468.9 & $1.56 \%$ \\
\hline & 5 & 0.65 & 812.5 & & 0.66618 & 832.73 & & \\
\hline & 6 & 0.65 & 812.5 & & 0.56549 & 706.86 & & \\
\hline & 1 & 0.6 & 768 & & 0.52981 & 678.16 & & \\
\hline & 2 & 0.6 & 768 & & 0.50098 & 641.25 & & \\
\hline 3804 (60\%) & 4 & 0.6 & 768 & 3253.7 & 0.74438 & 952.81 & 3223.2 & $0.94 \%$ \\
\hline & 5 & 0.6 & 750 & & 0.67302 & 841.28 & & \\
\hline & 6 & 0.6 & 750 & & 0.55279 & 690.99 & & \\
\hline & 1 & 0.55 & 704 & & 0.52884 & 676.92 & & \\
\hline & 2 & 0.55 & 704 & & 0.5 & 640.00 & & \\
\hline 3487 (55\%) & 4 & 0.55 & 704 & 2991 & 0.51222 & 655.64 & 2967.9 & $0.77 \%$ \\
\hline & 5 & 0.55 & 687.5 & & 0.67058 & 838.23 & & \\
\hline & 6 & 0.55 & 687.5 & & 0.54106 & 676.33 & & \\
\hline
\end{tabular}


TABLE 7: Optimal chiller loading comparison by LRELD and NNGA methods.

\begin{tabular}{|c|c|c|c|c|c|c|c|c|}
\hline \multirow{2}{*}{ Cooling load (RT) } & \multirow{2}{*}{ Chiller } & \multicolumn{3}{|c|}{$L R+E L D$} & \multicolumn{3}{|c|}{$\mathrm{NN}+\mathrm{GA}$} & \multirow{2}{*}{ Saving A - B (\%) } \\
\hline & & PLR & Load (RT) & Total $(\mathrm{kW})(\mathrm{A})$ & PLR & Load (RT) & Total (kW) (B) & \\
\hline \multirow{5}{*}{$6023(95 \%)$} & 1 & 0.95 & 1216 & \multirow{5}{*}{5301.3} & 0.99658 & 1275.62 & \multirow{5}{*}{4405.2} & \multirow{5}{*}{$16.90 \%$} \\
\hline & 2 & 0.95 & 1216 & & 1 & 1280.00 & & \\
\hline & 4 & 0.95 & 1216 & & 1 & 1280.00 & & \\
\hline & 5 & 0.95 & 1187.5 & & 1 & 1250.00 & & \\
\hline & 6 & 0.95 & 1187.5 & & 0.75024 & 937.80 & & \\
\hline \multirow{5}{*}{$5706(90 \%)$} & 1 & 0.9 & 1152 & \multirow{5}{*}{4986.5} & 0.99316 & 1271.24 & \multirow{5}{*}{4141.4} & \multirow{5}{*}{$16.95 \%$} \\
\hline & 2 & 0.9 & 1152 & & 1 & 1280.00 & & \\
\hline & 4 & 0.9 & 1152 & & 1 & 1280.00 & & \\
\hline & 5 & 0.9 & 1125 & & 1 & 1250.00 & & \\
\hline & 6 & 0.9 & 1125 & & 0.5 & 625.00 & & \\
\hline \multirow{5}{*}{$5389(85 \%)$} & 1 & 0.85 & 1088 & \multirow{5}{*}{4679.1} & 0.74536 & 954.06 & \multirow{5}{*}{3937.3} & \multirow{5}{*}{$15.85 \%$} \\
\hline & 2 & 0.85 & 1088 & & 1 & 1280.00 & & \\
\hline & 4 & 0.85 & 1088 & & 1 & 1280.00 & & \\
\hline & 5 & 0.85 & 1062.5 & & 1 & 1250.00 & & \\
\hline & 6 & 0.85 & 1062.5 & & 0.5 & 625.00 & & \\
\hline \multirow{5}{*}{$5072(80 \%)$} & 1 & 0.8 & 1024 & \multirow{5}{*}{4379.2} & 0.5 & 640.00 & \multirow{5}{*}{3696} & \multirow{5}{*}{$15.60 \%$} \\
\hline & 2 & 0.8 & 1024 & & 1 & 1280.00 & & \\
\hline & 4 & 0.8 & 1024 & & 1 & 1280.00 & & \\
\hline & 5 & 0.8 & 1000 & & 0.99804 & 1247.55 & & \\
\hline & 6 & 0.8 & 1000 & & 0.5 & 625.00 & & \\
\hline & 1 & 0.75 & 960 & & 0.50489 & 646.26 & & \\
\hline & 2 & 0.75 & 960 & & 1 & 1280.00 & & \\
\hline $4755(75 \%)$ & 4 & 0.75 & 960 & 4086.7 & 1 & 1280.00 & 3547.7 & $13.19 \%$ \\
\hline & 5 & 0.75 & 937.5 & & 0.67791 & 847.39 & & \\
\hline & 6 & 0.75 & 937.5 & & 0.56109 & 701.36 & & \\
\hline & 1 & 0.7 & 896 & & 0.5 & 640.00 & & \\
\hline & 2 & 0.7 & 896 & & 1 & 1280.00 & & \\
\hline $4438(70 \%)$ & 4 & 0.7 & 896 & 3801.6 & 0.99071 & 1268.11 & 3344 & $12.04 \%$ \\
\hline & 5 & 0.7 & 875 & & 0.5 & 625.00 & & \\
\hline & 6 & 0.7 & 875 & & 0.5 & 625.00 & & \\
\hline & 1 & 0.65 & 832 & & 0.5 & 640.00 & & \\
\hline & 2 & 0.65 & 832 & & 1 & 1280.00 & & \\
\hline $4121(65 \%)$ & 4 & 0.65 & 832 & 3523.9 & 0.61193 & 783.27 & 3177.9 & $9.82 \%$ \\
\hline & 5 & 0.65 & 812.5 & & 0.5826 & 728.25 & & \\
\hline & 6 & 0.65 & 812.5 & & 0.55279 & 690.99 & & \\
\hline & 1 & 0.6 & 768 & & 0.5 & 640.00 & & \\
\hline & 2 & 0.6 & 768 & & 0.9956 & 1274.37 & & \\
\hline 3804 (60\%) & 4 & 0.6 & 768 & 3253.7 & 0.5 & 640.00 & 3048 & $6.32 \%$ \\
\hline & 5 & 0.6 & 750 & & 0.5 & 625.00 & & \\
\hline & 6 & 0.6 & 750 & & 0.5 & 625.00 & & \\
\hline & 1 & 0.55 & 704 & & 0.5 & 640.00 & & \\
\hline & 2 & 0.55 & 704 & & 0.69208 & 885.86 & & \\
\hline 3487 (55\%) & 4 & 0.55 & 704 & 2991 & 0.55572 & 711.32 & 2912.3 & $2.63 \%$ \\
\hline & 5 & 0.55 & 687.5 & & 0.5 & 625.00 & & \\
\hline & 6 & 0.55 & 687.5 & & 0.5 & 625.00 & & \\
\hline
\end{tabular}


TABLE 8: Optimal chiller loading comparison by LRELD and ANFIS + GA methods.

\begin{tabular}{|c|c|c|c|c|c|c|c|c|}
\hline \multirow{2}{*}{ Cooling load (RT) } & \multirow{2}{*}{ Chiller } & \multicolumn{3}{|c|}{$\mathrm{LR}+\mathrm{ELD}$} & \multicolumn{3}{|c|}{ ANFIS + GA } & \multirow{2}{*}{ Saving A - B (\%) } \\
\hline & & PLR & Load (RT) & Total $(\mathrm{kW})(\mathrm{A})$ & PLR & Load (RT) & Total $(\mathrm{kW})(\mathrm{B})$ & \\
\hline \multirow{5}{*}{$6023(95 \%)$} & 1 & 0.95 & 1216 & \multirow{5}{*}{5301.3} & 0.87537 & 1120.47 & \multirow{5}{*}{4296.3} & \multirow{5}{*}{$18.96 \%$} \\
\hline & 2 & 0.95 & 1216 & & 0.87732 & 1122.97 & & \\
\hline & 4 & 0.95 & 1216 & & 1 & 1280 & & \\
\hline & 5 & 0.95 & 1187.5 & & 1 & 1250 & & \\
\hline & 6 & 0.95 & 1187.5 & & 1 & 1250 & & \\
\hline \multirow{5}{*}{$5706(90 \%)$} & 1 & 0.9 & 1152 & \multirow{5}{*}{4986.5} & 0.56549 & 723.8272 & \multirow{5}{*}{4052.9} & \multirow{5}{*}{$18.72 \%$} \\
\hline & 2 & 0.9 & 1152 & & 0.93939 & 1202.42 & & \\
\hline & 4 & 0.9 & 1152 & & 1 & 1280 & & \\
\hline & 5 & 0.9 & 1125 & & 1 & 1250 & & \\
\hline & 6 & 0.9 & 1125 & & 1 & 1250 & & \\
\hline \multirow{5}{*}{$5389(85 \%)$} & 1 & 0.85 & 1088 & \multirow{5}{*}{4679.1} & 0.5 & 640 & \multirow{5}{*}{3831.3} & \multirow{5}{*}{$18.12 \%$} \\
\hline & 2 & 0.85 & 1088 & & 0.75806 & 9703.32 & & \\
\hline & 4 & 0.85 & 1088 & & 1 & 1280 & & \\
\hline & 5 & 0.85 & 1062.5 & & 0.99902 & 1248.78 & & \\
\hline & 6 & 0.85 & 1062.5 & & 1 & 1250 & & \\
\hline \multirow{5}{*}{$5072(80 \%)$} & 1 & 0.8 & 1024 & \multirow{5}{*}{4379.2} & 0.51075 & 653.76 & \multirow{5}{*}{3625.8} & \multirow{5}{*}{$17.20 \%$} \\
\hline & 2 & 0.8 & 1024 & & 0.5 & 640 & & \\
\hline & 4 & 0.8 & 1024 & & 1 & 1280 & & \\
\hline & 5 & 0.8 & 1000 & & 0.99902 & 1248.78 & & \\
\hline & 6 & 0.8 & 1000 & & 1 & 1250 & & \\
\hline & 1 & 0.75 & 960 & & 0.5 & 640 & & \\
\hline & 2 & 0.75 & 960 & & 0.5 & 640 & & \\
\hline $4755(75 \%)$ & 4 & 0.75 & 960 & 4086.7 & 1 & 1280 & 3478.3 & $14.89 \%$ \\
\hline & 5 & 0.75 & 937.5 & & 0.88416 & 1105.2 & & \\
\hline & 6 & 0.75 & 937.5 & & 0.87195 & 1089.94 & & \\
\hline & 1 & 0.7 & 896 & & 0.5 & 640 & & \\
\hline & 2 & 0.7 & 896 & & 0.5 & 640 & & \\
\hline $4438(70 \%)$ & 4 & 0.7 & 896 & 3801.6 & 1 & 1280 & 3284.3 & $11.66 \%$ \\
\hline & 5 & 0.7 & 875 & & 0.93744 & 1171.8 & & \\
\hline & 6 & 0.7 & 875 & & 0.565 & 706.25 & & \\
\hline & 1 & 0.65 & 832 & & 0.55034 & 704.44 & & \\
\hline & 2 & 0.65 & 832 & & 0.5 & 640 & & \\
\hline $4121(65 \%)$ & 4 & 0.65 & 832 & 3523.9 & 0.63099 & 807.67 & 3195.8 & $9.31 \%$ \\
\hline & 5 & 0.65 & 812.5 & & 1 & 1250 & & \\
\hline & 6 & 0.65 & 812.5 & & 0.57527 & 719.09 & & \\
\hline & 1 & 0.6 & 768 & & 0.5 & 640 & & \\
\hline & 2 & 0.6 & 768 & & 0.5 & 640 & & \\
\hline $3804(60 \%)$ & 4 & 0.6 & 768 & 3253.7 & 0.59677 & 763.87 & 3048.2 & $6.32 \%$ \\
\hline & 5 & 0.6 & 750 & & 0.88172 & 1093.6 & & \\
\hline & 6 & 0.6 & 750 & & 0.52639 & 666.55 & & \\
\hline & 1 & 0.55 & 704 & & 0.5 & 640 & & \\
\hline & 2 & 0.55 & 704 & & 0.5 & 640 & & \\
\hline 3487 (55\%) & 4 & 0.55 & 704 & 2991 & 0.61975 & 793.28 & 2980.2 & $0.36 \%$ \\
\hline & 5 & 0.55 & 687.5 & & 0.56207 & 702.59 & & \\
\hline & 6 & 0.55 & 687.5 & & 0.56891 & 711.14 & & \\
\hline
\end{tabular}


TABLE 9: Optimal loading conditions of chiller system operated by ANFIS + GA method.

\begin{tabular}{ccc}
\hline & Type & Training \\
ANFIS & Generate FIS & Gird partition \\
& MF type & psigmf \\
& MF type & Linear \\
& Train FIS optim. methood & Hybrid \\
& Epochs & 100 \\
\hline \multirow{3}{*}{ GA } & Popsize & 300 \\
& Maxgen & 400 \\
& Crossover rate & 0.5 \\
\hline
\end{tabular}

\section{Conflict of Interests}

The authors declare no conflict of interests.

\section{References}

[1] Taiwan Green Productivity Foundation, Air Conditioning System Management and Energy Saving Manual, 2008.

[2] S.-C. Hu and Y. K. Chuah, "Power consumption of semiconductor fabs in Taiwan," Energy, vol. 28, no. 8, pp. 895-907, 2003.

[3] J. E. Braun, S. A. Klein, J. W. Mitcell, and W. A. Beckman, "Applications of optimal control to chilled water systems without storage," ASHRAE Transactions, vol. 95, no. 1, pp. 663-675, 1989.

[4] J. E. Braun, Methodologies for the design and control of central of cooling plants [Ph.D. thesis], University of Wisconsin, 1988.

[5] R. J. Hackner, J. W. Mitcell, and W. A. Beckman, "HVAC system dynamaics and energy use in buildings-part I," ASHRAE Transactions, vol. 90, pp. 523-535, 1984.

[6] Y.-C. Chang, J.-K. Lin, and M.-H. Chuang, "Optimal chiller loading by genetic algorithm for reducing energy consumption," Energy and Buildings, vol. 37, no. 2, pp. 147-155, 2005.

[7] P. P. Bonissone, R. Subbu, N. Eklund, and T. R. Kiehl, "Evolutionary algorithms + domain knowledge = real-world evolutionary computation," IEEE Transactions on Evolutionary Computation, vol. 10, no. 3, pp. 256-280, 2006.

[8] R. E. Haber and J. R. Alique, "Fuzzy logic-based torque control system for milling process optimization," IEEE Transactions on Systems, Man and Cybernetics Part C: Applications and Reviews, vol. 37, no. 5, pp. 941-950, 2007.

[9] D. Martín, R. del Toro, R. Haber, and J. Dorronsoro, "Optimal tuning of a networked linear controller using a multiobjective genetic algorithm and its application to one complex electromechanical process," International Journal of Innovative Computing, Information and Control, vol. 5, no. 10, pp. 34053414, 2009.

[10] W.-S. Lee and L.-C. Lin, "Optimal chiller loading by particle swarm algorithm for reducing energy consumption," Applied Thermal Engineering, vol. 29, no. 8-9, pp. 1730-1734, 2009.

[11] W.-S. Lee, Y.-T. Chen, and Y. Kao, "Optimal chiller loading by differential evolution algorithm for reducing energy consumption," Energy and Buildings, vol. 43, no. 2-3, pp. 599-604, 2011.

[12] A. Gajate, R. Haber, R. D. Toro, P. Vega, and A. Bustillo, "Tool wear monitoring using neuro-fuzzy techniques: a comparative study in a turning process," Journal of Intelligent Manufacturing, vol. 23, no. 3, pp. 869-882, 2012.
[13] C.-L. Chen, Y.-C. Chang, and T.-S. Chan, "Applying smart models for energy saving in optimal chiller loading," Energy and Buildings, vol. 68, pp. 364-371, 2014.

[14] ASHRAE, ASHRAE Handbook. HVAC Systems and Equipment Handbook, ASHRAE, 2000.

[15] Y.-C. Chang, "Optimal chiller loading by evolution strategy for saving energy," Energy and Buildings, vol. 39, no. 4, pp. 437-444, 2007.

[16] J.-S. R. Jang, "ANFIS: adaptive-network-based fuzzy inference system," IEEE Transactions on Systems, Man and Cybernetics, vol. 23, no. 3, pp. 665-685, 1993.

[17] Y. C. Chang, C. Y. Chen, J. T. Lu, J. K. Lee, T. S. Jan, and C. L. Chen, "Verification of chiller performance promotion and energy saving," Engineering, vol. 5, no. 1A, pp. 141-145, 2013. 


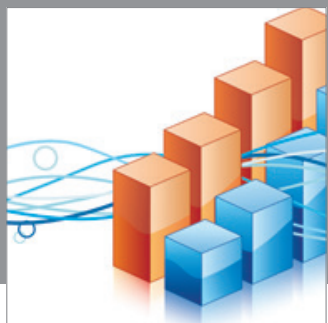

Advances in

Operations Research

mansans

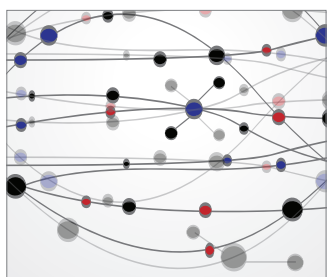

The Scientific World Journal
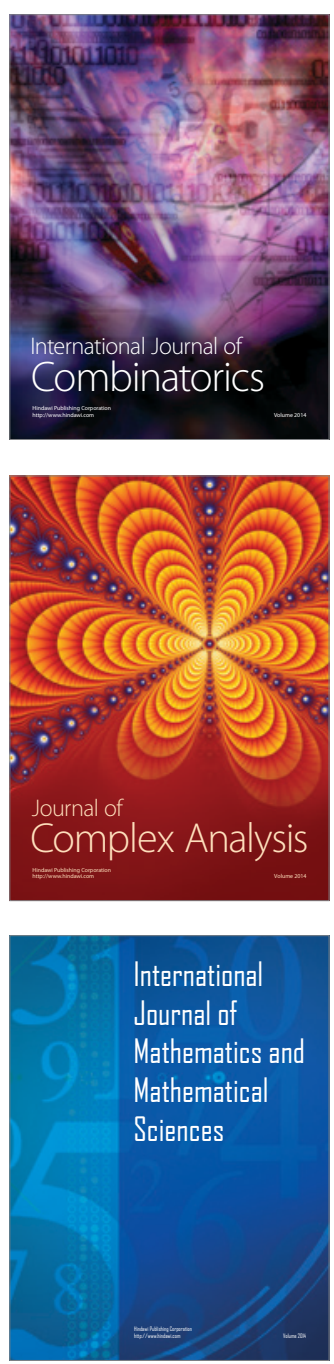
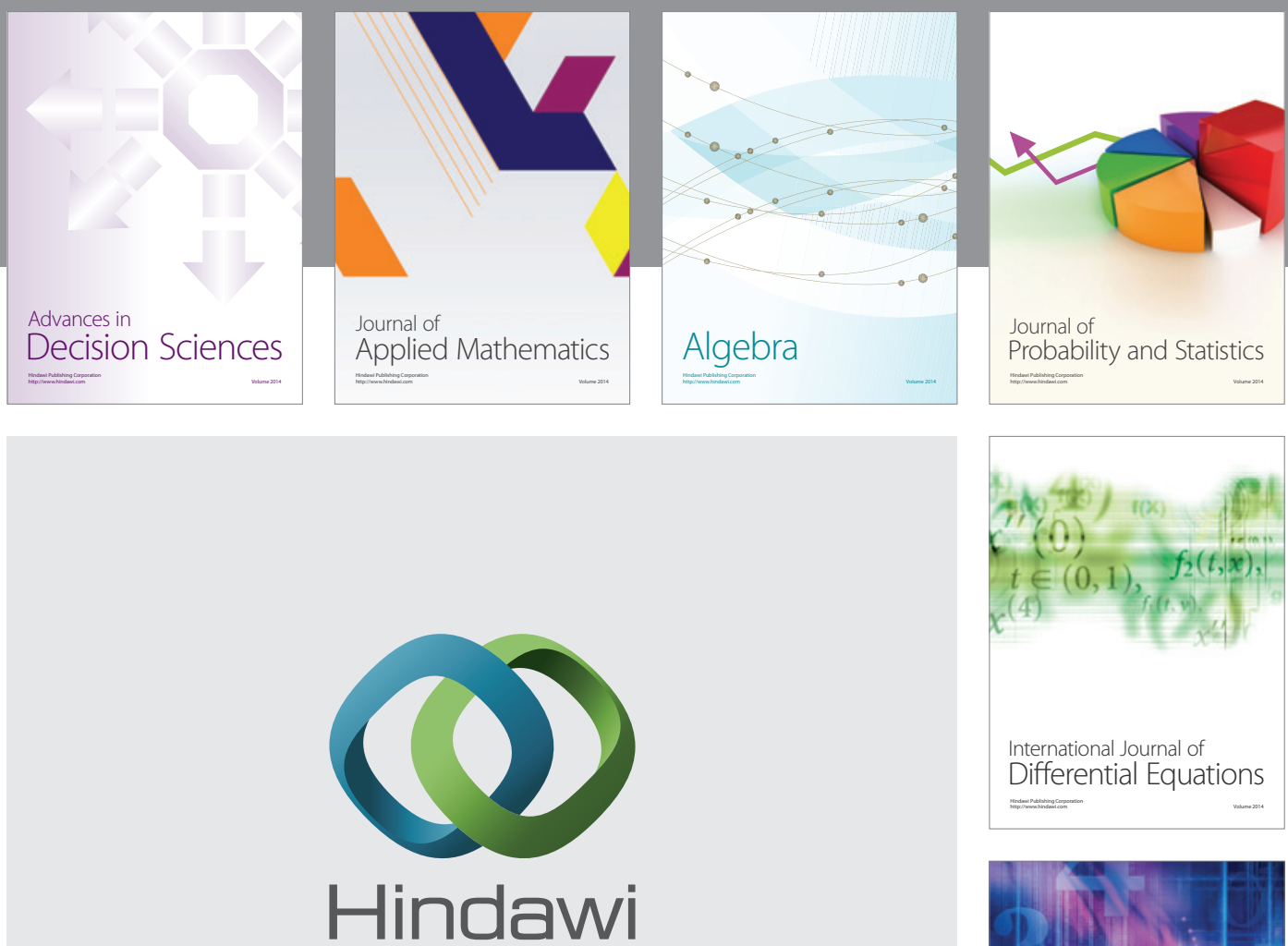

Submit your manuscripts at http://www.hindawi.com
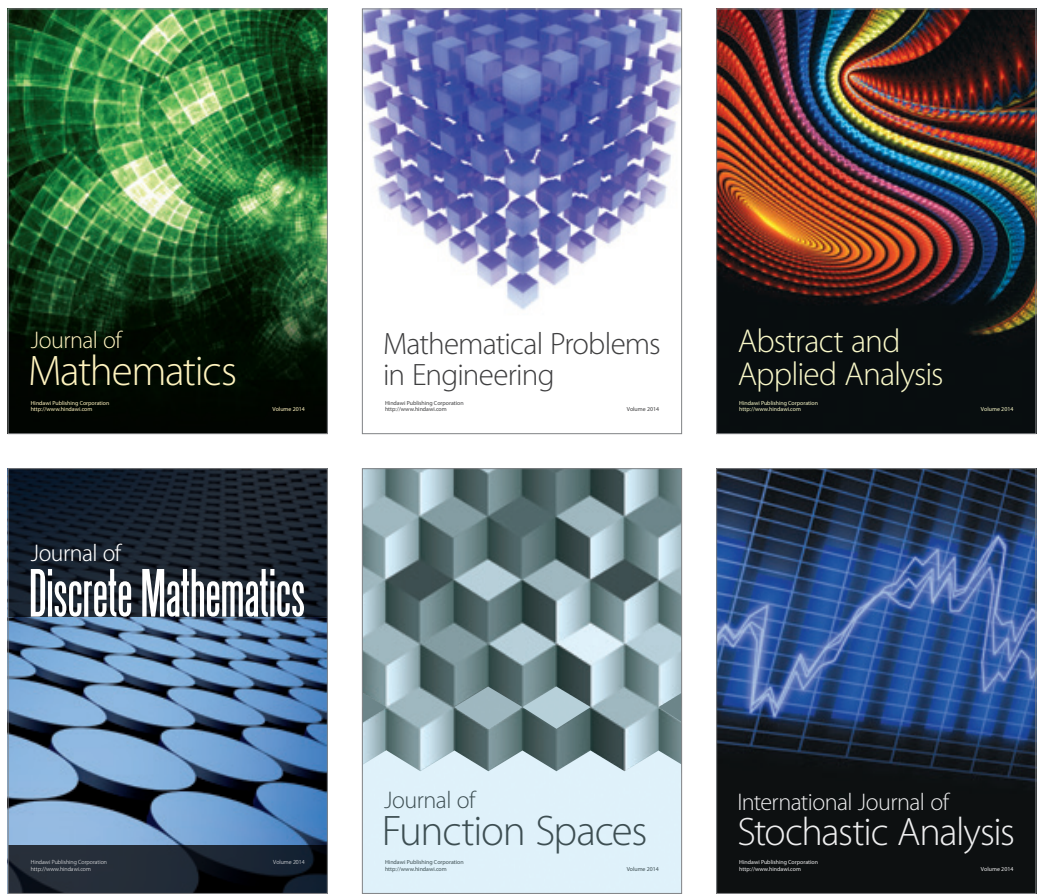

Journal of

Function Spaces

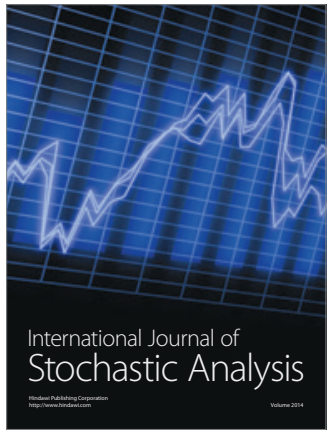

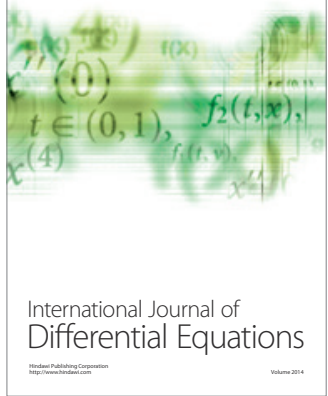
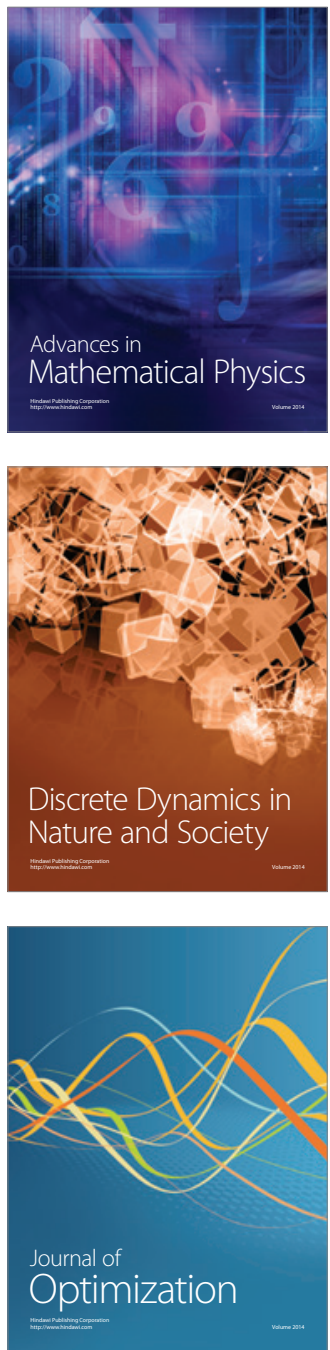